\title{
EM DIREÇÃO A UMA CONSTRUÇÃO PARTICIPATIVA DA POLÍTICA EDUCACIONAL: A PROPOSTA ALTERNATIVA DO PROJETO DE ÊXITO ESCOLAR EM VALPARAÍSO
}

\author{
HACIA UNA CONSTRUCCIÓN PARTICIPATIVA DE LA POLÍTICA EDUCACIONAL: \\ LA PROPUESTA ALTERNATIVA DEL PROYECTO DE ÉXITO ESCOLAR EN \\ VALPARAÍSO
}

\begin{abstract}
TOWARDS A PARTICIPATORY CONSTRUCTION OF EDUCATION POLICY: THE SCHOOL SUCCESS PROJECT IN VALPARAÍSO AS AN ALTERNATIVE PROPOSAL
\end{abstract}

María Teresa Flórez PETOUR ${ }^{1}$ José Miguel Olave ASTORGA ${ }^{2}$

RESUMO: O artigo propõe uma visão crítica acerca das atuais formas predominantes de construção da política educacional, a partir dos resultados de uma investigação que considera o caso do sistema de avaliação nacional do currículo no Chile (SIMCE). Em particular, nos focamos naqueles resultados que dão conta de uma conceitualização vertical da política educacional. Propomos que uma concepção como esta levanta problemáticas de justiça social, especificamente no âmbito da paridade de participação. Como proposta alternativa, se apresenta o caso de outro projeto, que consiste na construção participativa das bases para um sistema de avaliação em grande escala de orientação formativa, desenvolvido na comuna de Valparaíso, Chile. A partir desta experiência, se propõe a necessidade de avançar em direção a processos de construção da política educacional mais democráticos e, por isso, mais justos.

PALAVRAS-CHAVE: Política. Educação. Justiça. Participação. Avaliação.

RESUMEN: El artículo plantea una visión crítica acerca de lasactuales formas predominantes de construcción de la política educacional, a partir de los resultados de una investigación que toma el caso del sistema de evaluación nacional delcurrículumen Chile (SIMCE). En particular, nos centramos enaquellos resultados que dancuenta de una conceptualización vertical de la política educacional. Planteamos que una concepción como esta levanta problemáticas de justicia social, especificamenteenelámbito de laparidad de participación. Como propuesta alternativa, se presenta el caso de otroproyecto, que consiste enlaconstrucción participativa de las bases para un sistema de evaluación a gran escala de orientación formativa, desarrolladoenla comuna de Valparaíso, Chile. A partir de esta experiencia, se plantealanecesidad de avanzarhaciaprocesos de construcción de la política educacional más democráticos y, por ello, más justos.

PALABRAS CLAVE: Política. Educación. Justicia. Participación. Evaluación

${ }^{1}$ Universidad de Chile, Santiago - Región Metropolitana - Chile. Profesora Asistente, Departamento de Estudios Pedagógicos (DEP). ORCID: https://orcid.org/0000-0003-3704-726X. E-mail: mtflorez@uchile.cl

${ }^{2}$ Universidad de Chile, Santiago - Región Metropolitana - Chile. Profesor Adjunto, Centro Saberes Docentes. ORCID: https://orcid.org/0000-0002-9809-1304. E-mail: jose.olave@uchile.cl 
ABSTRACT: The article adresses currently predominant means of construction of education policy from a critical perspective, drawing on the results of a study that analyses the case of the national curriculum assessment system in Chile (SIMCE). In particular, we focus on those findings that reveal the predominance of a top-down approach to the understanding of education policy. We argue that this approach raises issues related to social justice, especifically in the dimension of parity of participation. As an alternative approach, a case related to a second project is presented, which consists of the participatory construction of the bases for a large-scale assessment system with a formative purpose, developed in the Municipality of Valparaiso, Chile. On the basis of this experience, the need for more democratic and, therefore, more socially just processes of policy construction is highlighted.

KEYWORDS: Policy. Education. Justice. Participation. Assessment

\section{Tensões e problemáticas da justiça participativa nosprocessos de construção da política educacional}

Nosso ponto de partida neste artigo é a crítica à implementação linear de cima para baixo das políticas educativas, orientadas desde um paradigma de justiça normal (FRASER, 2008), ou seja, que opera sob lógicas de construção de normas de convivência baseadas na produção de um saber/poder hegemônico, que gira em torno da ideia de sociedades homogêneas que se organizam sob a forma de Estados nacionais. A suspeita por uma outra racionalidade nos motiva a perguntar pela construção de políticas públicas que se desmarquem desta lógica hegemônica e que explorem horizontes de justiça orientados por considerara diversidade dos contextos e atores educativos.

Neste sentido, no presente artigo buscamos tensionar e problematizar as formas em que se compreende a articulação entre os gestores de política e as demandas por maior justiça entre os grupos que estão na base da vida social e cultural. Isso implica analisar criticamente a forma em que estas demandas são (ou não) adquiridas por agentes/instituições que elaboram políticas públicas em favor de colocar em norma, em prática social estas demandas de justiça que se geraram na vida social, econômica e cultural de cada sociedade. Daí emerge a necessidade de observar como se constroem políticas públicas desde uma perspectiva de justiça social, onde se integrem as diversas demandas que atualmente interpelam os sistemas educativos e que na atualidade não podem somente responder às pressões do mercado, como também devem integrar uma diversidade de abordagens, incluindo lutas pelas identidades de gênero, étnicas e geracionais. Esta diversidade nos obriga a buscar um paradigma de justiça no desenvolvimento de políticas educacionais que integre aquilo que a filosofia política distinguiu como demandas de justiça distributiva, de reconhecimento e de participação (FRASER, 2003). 
Quando decidimos olhar a elaboração de políticas públicas sob estes critérios inclusivos de justiça, trata-se de resolver as perguntas pelo conteúdo da justiça (que), as identidades representadas e suas demandas (quem), e a maneira em que se transformam em política pública estas demandas (como).Esta tarefa, no contexto do Ocidente, principalmente se juga no espaço público, que não está alheio de hegemonias já institucionalizadas, saberes culturais já validados e métodos de elaboração que tensionam para distintos grupos de interesse. Por isso, a busca de um princípio justo a respeito desta complexa elaboração se torna importante para assegurar um processo equitativo na formulação das normas. Propomos a análise deste processo de elaboração considerando o princípio de paridade participativa (FRASER, 2008) formulado por Nancy Fraser (2008) em sua obra Escalas de Justicia. A autora expõe um princípio que nos ajuda a superar problemas de inequidade na elaboração de normativas que superem tensões econômicas estruturais na distribuição ou possíveis reconhecimentos errôneos que sobrerepresentam a participação, silenciando as vozes relevantes. Dado que,

[...] a justiça necessita de acordos sociais que permitam a todos participar como pares na vida social. Desde a perspectiva de justiça, como paridade participativa, superar a injustiça significa desmantelar os obstáculos institucionalizados que impedem alguns de participar em um plano de igualdade com os demais, como sócios com plenos direitos na interação social (p. 117, grifos do autor).

Desde a área dos estudos de política educacional, existem diversas aproximações às perguntas: o porquê, por quem e o como dos dilemas que aqui conectamos com a dimensão de participação da justiça social. A nível internacional, desde várias décadas se construiu uma linha de desenvolvimento teórico investigativo em torno dos estudos críticos de política educacional (criticalpolicyscholarship), cujo esforço não se centra em realizar investigação para a política, como também $d a$ política, isto é, seu foco está no estudo da construção da política educacional como espaço de disputa pelo significado entre diversos grupos de interesse, mais que em propor medidas que melhorem as atuais políticas, dando por entendida a sua legitimidade. Já nos anos noventa, autores como Bowe, Ball e Gold (1992) propunham, um questionamento as leituras verticais ou lineares da política, que eles distinguem como um olhar que se intensifica a partir da instalação de lógicas gerenciais em educação, desde as quais se promove uma visão dos períodos de geração e implementação da política como espaços separados. Esta perspectiva linear descansa sobre supostos de unilateralidade na direção do processo de construção da política, onde um grupo de "especialistas" desenha certas diretrizes e os atores do nível local e a comunidade escolar são vistos como meros executores de dito desenho. 
Contra a naturalização desta forma de entender a política a partir daquela investigação que se propõe em função dela e de seu 'melhoramento', a tradição crítica centrou seus estudos na compreensão do funcionamento das atuais estruturas de governança "policêntrica" (BALL; JUNNEMAN, 2012), em que a política se compreende como um processo complexo de construção que ocorre em "múltiplas agências e lugares de produção de discursos" (BALL; EXLEY, 2010, p. 151). Assim, a política educacional é entendida como a interação entre diversos grupos de interesse que, com diferenciais de poder, buscam dominar a luta pelo significado daquilo que se entende como desejável em educação. Nesse cenário, a configuração dos discursos sobre educação se gera a partir da construção de redes complexas de atores que incluem políticos, organismos supranacionais, grupos de especialistas, instituições educativas, intelectuais, empresas educacionais, meios de comunicação, entre outros (BALL; JUNEMANN, 2012). A política, neste sentido, se ressignifica e se recontextualiza permanentemente, o que também inclui a escola, que não é vista aqui como o lugar da mera "implementação", mas sim como um espaço de entrelaçamento, onde a política volta a se reinterpretar, traduzir, se adaptar, resistir e ignorar (BALL; MAGUIRE; BRAUN, 2012), no contexto das relações de poder próprias da micropolítica da escola (BALL, 2012).

Questionar o olhar linear da concepção da política permite, por sua vez, repensar de maneira mais radical a forma em que a dimensão participativa da política educacional está sendo considerada. Primeiro, porque desnaturaliza a separação entre geração e implementação, desde a qual os autores da prática não têm um maior grau de incidência na formulação da política e, quando isso ocorre, se limita a processos de consulta sobre um texto já formulado. Em segundo lugar, abre o espaço para imaginar novas configurações de atores, que subvertam as atuais lógicas de poder nos processos de construção da política. O desenvolvimento deste tipo de estudos é ainda escasso a nível nacional e latino-americano, ainda que, nos últimos anos, pode-se falar de um desenvolvimento incipiente e crescente desta linha no Chile e em outros países. É a esta linha de estudos a que se adscreve o presente artigo.

Assim, neste artigo observaremos as dificuldades na elaboração de políticas públicas e sua posta em ação, identificando elementos que tensionam/favorecem a participação efetiva dos atores nestes processos. Nossas perguntas centrais, então, giram em torno de dois eixos de problematização: 1) Como ocorre atualmente o processo de construção da política educacional, em termos de quem participa dela, como o fazem e de que maneira se representam seus interesses?; 2) Como poderiam/deveriam se repensar os processos de construção da política educacional, em função de uma maior paridade de participação e, assim, de uma maior articulação com as demandas emergentes de justiça social? 
Em específico, apresentaremos resultados de dois projetos diferentes. O primeiro deles pergunta como se constrói a política educacional no Chile, utilizando o Sistema de Medição da Qualidade da Educação (SIMCE) como um caso. Isso permitirá, primeiro, realizar uma análise crítica acerca das configurações de atores e discursos que permeiam este processo, com ênfase na forma em que se considera ali a dimensão de participação de diversos grupos de interesse. Em segundo lugar, nos referiremos a um projeto desenvolvido na comuna de Valparaíso, Chile, cujo objetivo foi desenvolver um sistema alternativo de avaliação em grande escala, que disputasse o espaço que atualmente é dominado pelo SIMCE. A apresentação dessa experiencia pretende oferecer, desde uma iniciativa concreta, a abrir as possibilidades de consideração dos processos de construção da política educacional desde lógicas alternativas, em que exista uma maior justiça participativa, de acordo com os atuais horizontes emergentes de justiça social.

\section{Como ocorre atualmente o processo de construção da política educacional e quais são suas implicações para a justiça participativa?}

\section{Marco teórico-metodológico do projeto}

As descobertas que se apresentam nesta seção correspondem a um projeto de investigação no qual uma equipe interdisciplinar, coordenada pela primeira autora deste artigo, reuniu seus saberes nas áreas de estudo de comunicação e meios, educação e pedagogia, etnografia, sociologia da educação e análise do discurso, para responder à pergunta como se construí a política educacional no Chile, entendendo estes processos desde uma perspectiva crítica, complexa e dinâmica. Para isso, apelamos para o uso de uma "caixa de ferramentas" metodológicas variada, já que acreditamos, junto a autores como Larner (2011), que se torna imperativo hoje superar os limites disciplinares para poder responder os atuais dilemas que se apresentam na compreensão da política educacional.

Como marco teórico geral, nos situamos na noção de ciclo de política, elaborada inicialmente por Bowe, Ball y Gold (1992), que aborda a construção da política na sua trajetória sincrônica e no tempo, e considerando seus múltiplos domínios de circulação e problematização, os quais são sintetizados por estes autores nos âmbitos do contexto de influência, o contexto de produção dos textos de política e o contexto de prática. O contexto de influência se refere aos processos de mediação da política por parte de diferentes grupos de interesse no campo da educação, que buscam dominar a disputa pelo significado. Cabe destacar que, em desenvolvimentos posteriores da teoria do ciclo de política, se reconhece a necessidade de ampliar a construção da paisagem da política mas além do nacional, buscando representar 
nisso o papel que as organizações internacionais e outros organismos privados têm atualmente no processo de construção da política, ampliação que foi considerada neste estudo (LINGARD; SELLAR, 2013). O contexto de produção dos textos de política se refere à representação dos discursos em disputa através de sua codificação em documentos oficiais, instruções, discursos públicos, comunicações de imprensa, etc., onde se estabelecem as diretrizes daquilo que se pensa como o que deve ser a educação. Apesar de estarem redigidos em linguagem de bem público geral (BOWE; BALL; GOLD, 1992), estes textos estão longe de ser coerentes e neles persistem as marcas das tensões que norteiam a sua elaboração, frequentemente apagadas por meio de estratégias discursivas através de cujo análise é possível detectar que vozes, entre os grupos de interesse, foram finalmente as hegemônicas, e que perspectivas ficaram apagadas, silenciadas ou re-presentadas no processo. O contexto de prática, por sua vez, se refere às formas em que as comunidades escolares traduzem, reinterpretam, resistem a estas políticas, o que, em desenvolvimentos posteriores, Ball e seus colaboradores reconhecem como o entrelaçamento da política (BALL; MAGUIRE; BRAUN, 2012).

Como caso para nossa análise, escolhemos o Sistema de Medição da Qualidade da Educação (SIMCE), constituído por uma bateria de provas padronizadas nas áreas de Linguagem e Matemática e, para alguns níveis do sistema escolar, nas de História e Ciências Naturais. Escolhemos esta política devido ao papel crescentemente crucial que adquiriu, desde seus inícios em 1988 até o dia de hoje, como um pilar do modelo de mercado em educação no Chile, visto que se utiliza como o principal indicador de qualidade em dito mercado, e existem múltiplas consequências associadas aos seus resultados, na lógica de incentivos/consequências que caracteriza esta concepção dos sistemas educacionais, tendo incidência sobre os salários de professores, a imagem pública das escolas, o financiamento dos estabelecimentos e a possibilidade do seu fechamento (FLÓREZ, 2018). Neste sentido, o SIMCE constitui um caso com um alto potencial investigativo, em termos de como se construiu a política educacional de mercado no Chile, onde as últimas três décadas estão longe de superar este modelo, o intensificaram (BELLEI, 2015).

Assim, o projeto ao que aqui aludimos teve por objetivo compreender os processos de construção da política educacional no Chile, tomando o SIMCE como caso, indagando em seus atores principais, suas interações, interpretações e os discursos que circulavam entre eles acerca desta política.

Em termos de metodologia, tal como se destacou, o projeto colocou em ação uma combinação de ferramentas, como o fim de poder abordar o fenômeno com a complexidade requerida. Como fontes de análise, se consideraram textos midiáticos textos de política 
educacional, entrevistas com atores chave e trabalho etnográfico com escolas. Para os textos midiáticos, se realizaram duas rondas de seleção e análise de editoriais e notícias de dois jornais de circulação nacional: El Mercurio y La Tercera, considerando diversos pontos no período desde 2000 a 2014. No caso dos textos de política, se efetuou uma seleção inicial de 272 textos de especialistas, documentos legais e orientados aos usuários da política, considerando a trajetória do SIMCE desde 1988 a 2015. Logo de um escâner inicial dos textos, se selecionaram 7 deles, para uma análise em profundidade, como base no grau em que representavam as tensões da política para cada período. Com base nesta leitura inicial, também se selecionaram 12 autores chave, com os quais se realizaram entrevistas semiestruturadas, com a finalidade de enriquecer os dados obtidos nos documentos. Finalmente, a linha etnográfica do projeto abordou a tradução e interpretação desta política por meio de trabalho de campo sustentado em três estabelecimentos de uma mesma zona geográfica, com diferentes classificações, de acordo com seu desempenho em SIMCE (denominados aqui com os pseudônimos de "Escola Sul", "Escola Rosa" e "Escola Nova"). Como estratégias de analise, se combinou a análise de framing (ENTMAN, 2007), própria dos estudos de meios, à Análise Crítica do Discurso (ACD) e à codificação iterativa no caso específico do material etnográfico. A equipe interdisciplinar manteve diversas reuniões ao longo do projeto, com o fim de entrar em consenso sobre os aspectos metodológicos e de ir conectando os dados e descobrimentos a partir de uma interpretação coletiva.

Cabe destacar que, como se pode inferir, os achados derivados de um projeto desta envergadura são múltiplos, e o que aqui se apresenta é somente uma parte deles, em função dos eixos de discussão nos quais queremos dar ênfase neste artigo, isto é, o conteúdo da justiça (que) a representação de identidades e seus interesses (quem) e os modos em que se chega desde estas demandas à formulação de políticas (como).

\section{Principais descobertas em conexão com a dimensão de participação na construção da política educacional}

Uma primeira descoberta importante emerge do trabalho de análise de framing, especificamente em termos da consideração de que atores aparecem nos textos midiáticos e de política como fontes diretas, ou seja, são citados dentro destes textos, e aqueles que aparecem mediados ou "falados" dentro destes textos. Dentro dos textos de política, quem aparece predominantemente como fonte direta, são os autores que respondem às categorias de: Poder Executivo e Burocracia; Documentos Legais e Decretos; Especialistas; Organizações 
Internacionais. Desde 2003, os Centros de Pensamento e as Fundações Privadas aparecem também como fontes diretas relevantes. Por outra parte, aqueles autores que estão na categoria Comunidade Escolar, têm uma voz direta muito escassa nestes documentos, aparecendo, na grande maioria dos casos, como "falados" ou re-presentados no discurso das vozes dominantes, que são as que aludem ao que os docentes devem fazer ou estão fazendo de forma inadequada, ou como os pais e estudantes se veem beneficiados ou prejudicados por certas ações ou simplesmente o que se espera deles no sistema. De forma similar, dos 452 autores e das 691 fontes que se levantaram na análise de mídias entre 2000 e 2014, as principais vozes diretas correspondiam ao perfil de Poder Executivo e Burocracia e Especialistas. A presença de autores da categoria Comunidade Escolar como fonte direta é comparativamente menor e, além disso, sua presença limita-se a mostrar casos de escolas exitosas em seus resultados, apesar das condições de precariedade, ou da denúncia de casos de corrupção do sistema de avaliação.

Em termos de quais são as perspectivas predominantes destes autores, um achado importante diz relação com um padrão nos dados através do tempo, tanto nos textos de política, como nos textos midiáticos. Em nenhum destes textos o SIMCE como política é questionado, pelo contrário, se insiste em sua necessidade e se naturalizam seus efeitos positivos e sua credibilidade. Quando se reconhece a necessidade de mudanças nesta política, se alude a ajustes pontuais e factíveis ao instrumento, além da importância de intensificar seu impacto e seus efeitos.

No nível de análise em profundidade dos textos de política e de mídias, por outro lado, emergem achados relevantes em termos da forma em que aqueles autores que não tem uma voz principal são re-presentados, silenciados ou neutralizados por meio de uma série de estratégias discursivas. Uma delas denominamos de "positivização", e diz relação com a apresentação em termos positivos de aspectos percebidos por outros atores como negativos. O trabalho etnográfico foi consistente em revelar a forma em que a experiência das escolas com o SIMCE estava caracterizada por emoções associadas ao estresse, ao temor, à sensação de fracasso permanente, como ilustram as seguintes citações:

[...] Não, eu diria que caótico em alguns momentos. O estresse é muito (Professor Escola Rosa).

Então me preocupa o fato de que meus colegas, [...] os novos, os jovens, não tenham fonte laboral, porque você sabe que uma escola com maus resultados SIMCE pode ser até fechada (Professora Escola Nova).

[...] ai é como te desafiam. O Departamento de Educação nos chama, fazem conosco uma reunião com seus gráficos por escola. Então é como se algo não funcionasse bem. Se a gente baixou, porque aqui é oscilante [...] A gente se 
sente péssimo. Porque a gente trata de fazer o melhor (Professora Escola Rosa).

Estas experiências, derivadas dos processos de entrelaçamento da política nas escolas, não são apresentadas diretamente nos textos de política nem nas mídias. Pelo contrário, em documentos como o Relatório Executivo da Comissão SIMCE 2014 (2015) é possível ver a forma em que estas experiências são apresentadas como um aspecto positivo do SIMCE, no sentido que teria gerado "uma urgência pela melhora", que se interpreta como colocar em foco as aprendizagens. Junto com a positivização, vemos também, a partir destas citações, uma estratégia de silenciamento, visto que a voz dos atores das comunidades escolares em torno a esta vivência angustiante do SIMCE aparece apagada dos textos do espaço público, tanto mediático como de política.

Um momento particularmente interessante de analisar na trajetória da política do SIMCE é o ano de 2014, visto que, pela primeira vez, começam a aparecer autores que sustentam uma visão crítica deste sistema, tanto nos meios como nos textos de política. Até esse então, a discussão havia se mantido entre os autores antes mencionados como vozes predominantes, e as diferenças de perspectiva se limitavam a se os resultados deviam ser utilizados como um dispositivo de pressão e controle direcionado às escolas, ou como uma base para medidas de apoio econômico e pedagógico. Em 2014, no entanto, começam a ser mencionados atores como os estudantes secundários, Alto ao $\mathrm{SIMCE}^{3}$, ou Educação 2020, junto com um grupo de acadêmicos de tendência mais crítica, como vozes que propõe um questionamento mais profundo ao SIMCE e ao modelo educacional de mercado que o sustenta. A perspectiva destes atores, no entanto, além de seguir sendo minoritária em termos de aparição nos textos mediáticos, é apresentada a partir de estratégias de deslegitimação e desconfiança ao outro, desde as quais se apresenta em termos negativos. Assim ilustra o seguinte fragmento de um texto editorial, referido ao boicote ao SIMCE organizado pelos estudantes secundários:

[...] a tentativa de boicote à prova é absurda, toda vez que vai em desperdício deles mesmos e de seus próprios colégios. Ainda que seja um instrumento perfectivel e que deva ser complementado com outras medições, se trata de uma das poucas ferramentas com que conta, atualmente, o sistema de educação escolar para medir o nivel de aprendizagem dos estudantes, e é um insumo que permite conhecer quais são seus avanços e suas debilidades formativas, o que permite ir corrigindo os processos educacionais. Por sua vez, se trata de um mecanismo que proporciona aos pais informação útil na escolha do colégio para seus filhos; também se utiliza como fator na entrega de subvenções por rendimento"; "Os estudantes devem assumir que ações

${ }^{3}$ A melhor tradução seria abaixo ao SIMCE! 
deste tipo são incondizentes e refletem uma inconsistência com suas próprias demandas que apontam a fortalecer o ensino escolar (Editorial A Terceira sobre a resistência dos estudantes diante do SIMCE).

Junto com a já aludida naturalização dos efeitos positivos do SIMCE e suas políticas associadas, e com isso do modelo de mercado em educação, e a limitação de seus aspectos problemáticos a ajustes pontuais de tipo técnico, observa-se, neste fragmento, a apresentação em termos negativos das demandas dos e das estudantes. Junto com isso, se coloca em ação uma estratégia de apropriação da consigna que caracterizou os movimentos estudantis dos últimos anos por uma educação de qualidade para todos, ao destacar que o SIMCE seria uma ferramenta a favor destas demandas, o que converteria sua ação de protesto em um absurdo.

No mesmo período, o Relatório Executivo da Comissão SIMCE 2014 (2015), por sua vez, destaca na sua introdução que a convocatória desta comissão para revisar criticamente o SIMCE está motivada, entre outros fatores, pelas demandas destes novos atores que aparecem no panorama da política, buscando disputar o contexto de influência. Neste sentido, há uma aparente abertura para escutar a perspectiva destas novas vozes. Ao analisar o documento, porém, observa-se, primeiro, que a composição dos membros da comissão inclui os atores que foram as vozes predominantes ao longo da trajetória desta política, e dela ficam excluídos estes atores, ou, no caso dos professores, ficam representados minoritariamente. Assim, se inclui dentro dos convidados as seções da comissão, cujos membros escutariam sua perspectiva em função de considerá-la em suas recomendações. Ao analisar o documento, contudo, vemos que dos estudantes somente se destaca em uma nota de rodapé que foram convidados, mas que não puderam comparecer às reuniões. Com respeito às organizações como Alto ao SIMCE, se indica que sua perspectiva não se destaca explicitamente no documento, mas sim que suas visões são resgatadas ao longo do seu conteúdo, apagando assim da superfície textual o ponto de vista que pôde ter proposto este ator, ficando invisível para o leitor. Finalmente, a voz dos docentes é novamente falada, já que se apresenta em uma síntese, que reúne em um mesmo parágrafo o olhar de sustentadores, diretores e professores, como se todos estes atores estivessem de acordo e no existissem neste olhar matizes nem desacordos. Assim, o que inicialmente se apresentava como uma abertura a novos atores no processo de construção da política do SIMCE, termina sendo um gesto, orientado a gerar uma ilusão de consenso, neutralizando a perspectiva das vozes dissidentes.

Em termos de justiça participativa, seguindo a Fraser (2008), a partir desta análise, vemos primeiro que a construção da política educacional no Chile segue os padrões tradicionais em termos de como se define o porquê da política pública. Este papel fica 
centrado nos "especialistas" da comunidade científica nacional e internacional, em articulação com atores governamentais, e é dali que se decidem os parâmetros dos problemas a atender, os quais se mantêm no marco do sistema do mercado em educação e legitimam as políticas que o sustentam, entre elas, o SIMCE. A voz de outros atores é apropriada pelos atores políticos e científicos, a fazendo funcional à lógica desde a qual se pensa a política. Quando a dissidência se faz mais visível, estas vozes são neutralizadas, apropriadas e deslegitimadas ficando sua experiencia e perspectiva crítica apagada do espaço de disputa pelo significado, o que se facilita pelo acesso privilegiado dos atores dominantes do discurso público mediático, acadêmico e dos textos de política. Não existe, então, uma paridade de participação (FRASER, 2008) desde um diálogo legítimo que considere a todos os grupos de interesse, especialmente daqueles em maior desvantagem de representação, desde a etapa de desenho da política. Os estudantes, as organizações sociais, os docentes e a academia crítica não teriam condição de membro nos processos de construção da política - podemos ver, por exemplo, na composição das Comissões SIMCE de 2003 e 2014 -, pois sua participação limita-se à consulta ou à audiência ou a uma presença minoritária, sem garantias da consideração de sua perspectiva na tomada final de decisões. Não resulta estranho, então, que estes atores vivam estas políticas como alheias, externas, punitivas e pouco relevantes para sua prática cotidiana, pois não nascem de um diagnóstico que sintam como próprio. Nos textos de política, no entanto, esta distancia é apresentada como falência atribuída aos usuários do SIMCE, que não saberiam interpretar ou utilizar adequadamente seus resultados.

Com respeito a este ponto, há um último conjunto de descobertas relevantes que queríamos agregar à discussão em torno da participação, que diz relação com o que Fraser (2008) destaca como a essência da identidade do outro entre os obstáculos para uma paridade participativa. As entrevistas do projeto revelam a forma em que os diversos atores do panorama da política do SIMCE se percebem entre si e acreditamos que nisso radica outro problema central na busca de uma justiça participativa. O Quadro 1 apresenta o contraste entre a forma em que uma entrevistada em categoria de Especialista e com papéis de Poder Executivo e Burocracia vê o papel dos professores na construção da política, e a forma em que um exdirigente do Colégio de Professores vê uma das especialistas técnicas a cargo da criação do SIMCE: 
Quadro 1 - Contraste de entrevista

"Entrevistadora: Como você vê que deveria ser e o que é o papel dos professores, na construção da política educacional? Como você acredita que é e como deveria ser, conforme o teu critério?

Entrevistada: Olha, é bem complicado o tema dos professores no Chile, porque os professores, principalmente os professores da rede Básica, sabem bem pouco, ou seja, é difícil que eles possam contribuir com muita informação a uma política bem desenhada. Eu gastaria todo o dinheiro do mundo em formar bem aos professores, mas sei que é super difícil."

(Entrevista com perfil de especialista, membro do governo e fundações privadas de educação)
"Entrevistado: eu acredito que há um peso do técnico sobre a vida, então, com todo o respeito que eu tenho à (nome da acadêmica responsável pelo desenho do SIMCE). [Ela] só tinha uma visão técnica, a vida real não estava inserida aí, e na vida real, essa técnica funcionou como funcionou e isso ela veio a vivenciar depois. Mas já na comissão ela tinha um pouco, como que isso a orientava para dirigir a comissão."

(Entrevista a antigo dirigente área de estudos Colégio de Professores, participante em Comissiones SIMCE)

Fonte: elaboração própria

Observamos neste contraste ilustrativo dois padrões que emergiram nas entrevistas que os docentes aparecem apresentados na linguagem dos especialistas como atores desprovidos de um conhecimento relevante nos processos de formulação da política. Ao inverso, observamos como os especialistas são representados na linguagem dos docentes como pessoas possuidoras de um conhecimento técnico que não teria utilidade o sentido na prática, se encontrando distante deste saber experiencial. Não é possível, assim gerar uma interação genuína em que exista um reconhecimento mútuo entre os atores, do qual se derive uma paridade de participação no desenho da política pública. Também vemos no seguinte fragmento a forma em que uma entrevistada do perfil de Especialista técnica do SIMCE vê seu trabalho como dissociada das intenções da política:

Ou seja, eu acredito que o que se deve olhar são as consequências, não a prova. Se a prova está bem construida e qual é o objetivo de aplicá-la, ou seja, as consequências são decisões políticas [...]. Então, se os desvios políticos, quanto incidem as consequências políticas, não é certo?, de política. Mas ou seja as grandes políticas, não é certo? tem um marco que vai más além do SIMCE de todas as maneiras (Entrevista à Especialista Técnica SIMCE).

É possível observar neste trecho que a especialista limita seu trabalho ao instrumento, como se este pudesse se ver dissociado dos propósitos que a política lhe atribuiu desde um princípio, atribuindo a responsabilidade pelos problemas associados ao SIMCE aos gestores de política. Assim, seu papel fica de alguma maneira protegido e restrito, desde uma intenção científico-técnica de caráter neutro, dissociada da discussão política ao serviço da qual sempre 
esteve posto o SIMCE. Finalmente, a seguinte citação de um ator relevante em instâncias de caráter governamental ilustra a forma em que este compreende o papel dos movimentos sociais na construção da política:

Ou seja, os movimentos se traduzem em certas ideias forças, que não tem nunca e nunca é a pretensão, um movimento o que pode levantar são demandas, pode articular um discurso, [para] soluções técnicas, mas parte do oficio dos movimentos é seguir esse exercício de influência e de pressão. Então, muitas vezes, quando você discute, não pode sair do slogan e o slogan soma vontades, mas vontades que pensam diversamente e de maneira muito diferente. E quando você o expressa em soluções técnicas, olha o que passa agora, o que termina em que ninguém está conforme e de acordo com nada (Entrevista a Especialista com papel de governo em política educacional).

O fragmento coloca de manifesto a concepção dos especialistas técnicos e atores governamentais como os únicos chamados para desenhar, em termos concretos, as soluções que, desde a política, se proporiam em resposta às demandas dos atores sociais. A partir desta visão, que restringe o papel dos movimentos como mero exercício de pressão e levantamento de ideias gerais, os atores das comunidades escolares e a sociedade civil não deveriam nunca ser chamados para ter um papel ativo na formulação de políticas. Isso se traduz, como já vimos, em soluções técnicas que não são percebidas nem ligadas pelos atores da comunidade escolar como coerentes com as necessidades e problemas que eles diagnosticam.

Até que ponto, e como seria possível repensar os processos de construção da política educacional, num sentido que supere os atuais obstáculos de justiça participativa, é o que abordaremos na seguinte seção, a partir dos achados de outro projeto, que apresenta uma experiência concreta de ressignificação dos processos de participação na Comuna de Valparaíso, Chile.

\section{Como poderiam/deveriam se repensar os processos de construção da política educacional em função de uma maior justiça participativa?}

\section{Repensar a política a partir do sentido coletivo do projeto Êxito Escolar}

Quem poderia se opor a esta ideia de elaborar políticas públicas inclusivas, que coloquem no centro meninos, meninas e jovens da comuna de Valparaíso, que não desertem e vejam no sistema escolar público uma oportunidade significativa para suas vidas. O problema de elaborar uma política destas características não estava no sentido da proposta, mas sim, em como se executava, garantindo em seu processo paridade participativa para todas e todos os 
atores. Neste contexto, a Prefeitura Cidadã de Valparaíso abre o espaço de oportunidade política para uma proposta alternativa, promovendo o Projeto Êxito da Trajetória Escolar, que considera como uma de suas linhas de ação a prática de um Sistema de Avaliação Comunal, co-construído com os atores da Corporação de Educação Municipal (CORMUVAL). Para dar operação a esta linha de ação, o ator municipal busca a colaboração com uma equipe de acadêmicos da Universidade do Chile, junto com um grupo de profissionais de diferentes áreas participantes do coletivo Alto ao SIMCE (AaS), os quais compartilham a crítica aos sistemas de avaliação padronizados e a necessidade desenvolver uma educação mais inclusiva. Um primeiro ponto a considerar como divergente das lógicas imperantes, então, é que, desde o início do projeto, quatro atores (ator político municipal, comunidades escolares, organizações sociais e academia) se reúnem numa relação dialógica horizontal, em função de um objetivo comum. Isso a partir de instâncias de trabalho de terreno em cada uma das escolas que se integram ao projeto, de espaços que reúnem a todas as escolas (plenárias) e de momentos de interação entre os atores do nível comunal e das comunidades escolares. A seguinte citação é ilustrativa da sensação do sentido coletivo que predomina em quem participa:

Os que estamos aqui buscamos ferramentas para transformar nossas práticas avaliativas, para mudar o paradigma e compreender que a avaliação deve ser parte do processo formativo de todas e todos os estudantes e que dê conta da aprendizagem significativa de todos e todas, professores e estudantes (Oficina plenária 1, 2018).

Como primeiro passo deliberativo na construção da política, se realizou um diagnóstico participativo, que deriva na elaboração de um conjunto de princípios como marco ético-político da proposta. Este diagnóstico se construiu buscando em oficinas de campo e plenárias as perspectivas de coordenadores pedagógicos e diretores de CORMUVAL, professores/as, membros das equipes de gestão e do Programa de Integração Escolar - PIE dos estabelecimentos e dos estudantes. Desde um diagnóstico crítico, compartilhado da cultura avaliativa predominante na avaliação externa e de sala de aula, os princípios definidos têm relação com um sistema de avaliação comunal que espera ser: contextualizado à comuna e a cada estabelecimento; respeitoso com a diversidade em suas diferentes dimensões; com um propósito unicamente formativo; democrático e participativo; e centrado na progressão de aprendizagens significativas. Isso em contraposição a uma visão dos sistemas atuais como genéricos, homogeneizantes, de lógica somativa e punitiva, verticais e externos, além de centrados no entretenimento de tarefas de rotina. 
A partir destes princípios, se elaboram critérios de avaliação comunal, os quais emergem de um processo interativo de reflexão contextualizada do currículo nacional, considerando a pertinência destas aprendizagens no contexto de vida dos/as estudantes de Valparaíso, como também o significado destas aprendizagens para a participação como cidadãos com plenos direitos. Neste sentido, o constructo da avaliação surge de uma construção coletiva, que redunda em uma sensação de são "nossos" critérios, evitando a sensação de distância que geram os padrões externos.

Com base nestes critérios, são as próprias escolas que desenham seus cenários de avaliação, permitindo assim, a contextualização e o respeito pela diversidade, ao estar constituídos por séries de atividades no tempo que favorecem a demonstração de aprendizagens de maneiras variadas, assim como monitorar e retroalimentar sua progressão no tempo. Os processos associados à validez e à confiabilidade destes cenários ficam nas mãos dos próprios profissionais dos estabelecimentos e a CORMUVAL, que em painéis locais por escolas e painéis comunais, discutem a coerência dos cenários com os critérios e regulam a calibragem do seu juízo avaliativo, além de sistematizar a informação acerca das aprendizagens evidenciadas e desenhar a tomada de decisões com base nisso.

Estas instâncias são reconhecidas pelos mesmos participantes como espaços de alta profissionalização, já que se validam decisões entre professores e professoras, se enriquecem práticas e se calibra o juízo avaliativo, graças ao diálogo e à retroalimentação entre pares. Ademais, estes espaços têm a particularidade de romper com a tradicional hierarquização na tomada de decisões, já que o diálogo é horizontal e argumentativo, baseado na confiança e solidariedade. Assim ilustra a seguinte citação:

[...] destaco a conversação que se gerou entre as equipes, promovida desde uma reflexão prévia da própria experiência dos líderes pedagógicos e coordenadores nas escolas. Esta instância permite desenvolver conviç̧ão e clareza no que se deve fazer (Professor Participante Painel Comunal, 2018).

Outra virtude observada do projeto na integração constante das visões de cada estabelecimento com as comunais e nacionais, o que evita reduzir a discussão somente a âmbitos particulares. A articulação de baixo para cima é própria de um sistema que deseja evitar o reducionismo de enfoques ou a generalização nas decisões, tal como exemplifica a seguinte citação:

[...] descentralizar o olhar para os estabelecimentos dando ênfase aos processos de ensino e aprendizagem dos estudantes, assim poder educar não somente os estudantes, como também todo o sistema educativo, incluindo os 
apoderados, para romper com o antigo paradigma da avaliação (Síntese Plenária 3, 2018).

O empoderamento que produz a participação em distintos espaços e com atores diversos gera um modo de fazer política educativa que convoca sentidos coletivos, como também o reconhecimento de distintos enfoques e posturas. Estas instâncias foram definindo o porquê da política, quem participa e como elaborá-la. Quais são aqueles obstáculos à participação se foram sorteando e que possibilidades se abrem ao poder sorteá-los, são pontos que serão revisados no seguinte trecho.

\section{Superando obstáculos, promovendo a participação}

Uma primeira discussão é evitar alguns problemas referidos ao porquê da política, desde uma operação que entregue sentido ao critério de paridade participativa, onde todos os sujeitos que participam da implementação de uma política pública possam ser incluídos em condições de igualdade deliberativa. Por isso, a primeira consideração é como se vão definir os conteúdos daquilo que se deseja elaborar como política pública. Desde aqui, o Projeto Êxito escolar tratou de se esquivar de alguns problemas que, desde a perspectiva tradicional de elaboração e implementação, frequentemente são invisibilizados. Víamos nos resultados do primeiro projeto que nutre este artigo que a lógica tradicional de construção da política pública destaca sua origem nos parâmetros que a comunidade científica nos entrega como causas do problema de injustiça, ou seja,são possíveis de visibilizar somente aqueles problemas que as ciências sociais e seus métodos podem suportar. O projeto Êxito Escolar, pelo contrário, teve a vantagem de assumir um enfoque multidimensional e uma construção coletiva dos princípios que guiam o projeto, dando, deste modo, uma compreensão mais ampla do problema. Assim, se tenta superar, por exemplo, a crença de que a inversão permanente em avaliações de altas consequências com implicações para a pedagogia e a cobertura do plano de estudos, pode elevar por si só os resultados educativos (LINGARD; KEDDIE, 2013; STOBART, 2010).

Outro aspecto importante para evitar um reducionismo de enfoque, foi a busca por assegurar, de maneira institucional, o espaço de participação dos distintos atores: professores, diretores, coordenadores pedagógicos, que são, ao mesmo tempo, funcionários da corporação municipal, por meio da atribuição de horas e espaços protegidos aos participantes, sob um critério inclusivo.

Outra dimensão relevante diz relação com a determinação de quem deve participar. A partir dos resultados da investigação antes exposta, víamos que uma problemática está dada 
pela crítica à determinação da condição membro. Isso porque a política pública determina arbitrariamente quem deve ser parte da elaboração e implementação da política, gerando o que Nancy Fraser (2008) denomina como uma "representação falida da política ordinária", já que, habitualmente, os convocados são parte do corpo de governança hegemônico ou participam de estruturas de saber e poder que lhes permitem participar na elaboração de políticas públicas. Víamos na seção anterior a forma em que este olhar tradicional vai deixando de fora a diferentes atores que são propriamente afetados e que tradicionalmente não têm poder deliberativo neste tipo de questões.

A experiência do projeto Exxito Escolar pode saltar este obstáculo desde uma lógica diferente, já que o princípio que guiava a determinação de quem deve participar na construção de uma política buscava representar a todos os atores afetados. O Projeto de Êxito Escolar levanta um critério de participação mais inclusivo, ao integrar, por exemplo, a participação de Alto ao SIMCE, grupo composto por diferentes atores sociais, de diversas profissões de origem, que têm em comum uma leitura crítica aos modos hegemônicos de construção política, em particular sobre as políticas de avaliação padronizada. Também, neste marco, a participação da academia não se concebe desde uma hierarquia de saberes, mas sim como um ator a mais que contribui ao diálogo de saberes políticos, científicos, experienciais, pedagógicos, todos com igual valor para o projeto. Este princípio de participação que inclui todos e todas as afetadas, sobrepassa o enquadramento inicial da condição de membro, já que se integram meninos e meninas em toda sua diversidade, professores, diretores e funcionários do município, ao mesmo tempo participam acadêmicos, junto a grupos sociais como $\mathrm{AaS}^{4}$. Um ponto ainda pendente do projeto, neste sentido, é uma maior inclusão dos pais e apoderados como um ator relevante. Esta estrutura local está constituída pela experiência intersubjetiva de uma afetação comum, o que se poderia entender por uma estrutura de governança coletiva, que inclui aos distintos atores em sua diversidade de afetação, dada uma problemática que os aflige de maneira individual e coletivamente.

Como revisávamos na seção anterior, um terceiro obstáculo que pode afetar a paridade participativa é o problema da essência da Identidade (LINGARD; KEDDIE, 2013; KEDDIE, 2012; FRASER, 2008). Desde a lógica tradicional, revisamos a forma em que as visões estereotipadas acerca da identidade e o papel do Outro na construção da política pública, não contribuía para um diálogo em igualdade de condições e que reconhecesse a voz dos diversos atores no processo. Neste caso, o princípio que se utilizou no projeto de Êxito Escolar é o de

${ }^{4}$ Sigla que representa um coletivo de profissionais denominado Alto Al Simce. 
diálogo de saberes (DE SOUSA, 2014), que permite gerar processos de reconhecimento recíproco. A experiência de um/a acadêmico/a com seu grupo de tutores é colocada em discussão junto ao saber que possuem os professores e professoras, e é tão válido como o saber dos estudantes que participam e são sujeitos de uma política educativa, tal como se expressa na seguinte citação:

CORMUVAL reúne em torno deste projeto piloto quatro saberes distintos: o saber pedagógico de cinco escolas da comuna que experimentam dia a dia os problemas do fracasso e o êxito escolar; o saber acadêmico do Departamento de Estudos Pedagógicos (DEP) e o Programa de Educação Contínua para o Magistério (PEC, atualmente Centro Saberes Docentes), ambos da Universidade do Chile, que conhecem em profundidade outras maneiras de avaliar como, por exemplo, o modelo de Avaliação para a Aprendizagem (EpA); o saber crítico em direção ao sistema de padronização que a Campanha Alto ao SIMCE elaborou contra políticas como o SIMCE e os obstáculos que gera em poder gerar processos formativos; e, o saber de liderança e gestão das profissionais e dos profissionais que trabalham em CORMUVAL (Relatório Final, Universidade do Chile, 2018).

Para respeitar estas experiências, o diálogo público e deliberativo se converte em uma ferramenta que permite o intercâmbio de pontos de vista, produzir acordos, como também reconhecer dissensos, evitando a idealização de cada grupo identitário participante como um todo homogêneo, por exemplo, se torna um mérito do projeto poder sistematizar tanto os acordos como os desacordos, questão que, em definitiva, produz um processo de reconhecimento recíproco não subalterno (OLAVE, 2018), resguardando não gerar hierarquias de poder em sua própria execução. O reconhecimento destas diversidades pode ajudar a construir melhores políticas educacionais, sem deixar de entender que estas problemáticas são parte de processos mais estruturais, neste sentido, "é importante que esta sugestão não trate o reconhecimento errôneo como um $<<$ dano cultural autônomo $>>$, mas sim que compreenda a sua localização dentro das condições sociais e estruturais mais amplas nas que a má distribuição impede seriamente a participação e o êxito escolar" (LINGARD; KEDDIE, p. 270).

\section{Considerações finais}

Os casos abordados neste artigo permitem visualizar, pela evidência empírica, as problemáticas de justiça participativa que se derivam dos atuais modos de pensar a construção de políticas educacionais, ancorados em perspectivas gerenciais e verticais, a partir das quais emergem obstáculos para a participação, derivados principalmente da forma em que se define o porquê, quem, como e desde que visão do Outro se desenham e colocam em ação estas 
políticas. Também podemos ver um caso concreto em que estes obstáculos se superam, ao subverter as lógicas tradicionais de construção da política. O Quadro 2 apresenta, de forma sintética, a comparação entre estas duas lógicas.

Quadro 2 - Síntese comparativa de aproximações à construção de políticas

\begin{tabular}{|c|c|c|}
\hline $\begin{array}{c}\text { Dimensões } \\
\text { justiça } \\
\text { participativa }\end{array}$ & $\begin{array}{c}\text { Lógica atual } \\
\text { Construção de políticas }\end{array}$ & $\begin{array}{c}\text { Lógica alternativa } \\
\text { Construção de políticas }\end{array}$ \\
\hline Por que & $\begin{array}{l}\text { Os problemas, o diagnóstico e as } \\
\text { decisões relacionadas com o desenho } \\
\text { da política respondem à lógica } \\
\text { tradicional, em que o conhecimento } \\
\text { técnico-científico derivado de } \\
\text { especialistas é o único parâmetro, } \\
\text { além do modelo educacional que se } \\
\text { proponha desde as autoridades. }\end{array}$ & $\begin{array}{l}\text { Se co-constrói um diagnóstico } \\
\text { participativo, que considera as } \\
\text { problemáticas levantadas por } \\
\text { diferentes atores relevantes em relação } \\
\text { com o âmbito que compete a uma } \\
\text { política determinada, e é, dali que se } \\
\text { levantam princípios e dispositivos para } \\
\text { o desenho da política, que mantem seu } \\
\text { caráter participativo. }\end{array}$ \\
\hline Quem/como & $\begin{array}{l}\text { Os especialistas e atores } \\
\text { governamentais são maioritariamente } \\
\text { considerados com condição de } \\
\text { membro no conjunto de atores que } \\
\text { tomam decisões acerca do desenho da } \\
\text { política, enquanto que os atores das } \\
\text { comunidades escolares, das } \\
\text { organizações sociais e da academia } \\
\text { crítica são incluídos } \\
\text { minoritariamente, em uma lógica de } \\
\text { consulta sobre políticas já } \\
\text { desenhadas. A visão tradicional } \\
\text { aborda, além disso, aos atores da } \\
\text { prática como quem têm como papel } \\
\text { principal implementar as políticas } \\
\text { adequadamente. }\end{array}$ & $\begin{array}{l}\text { A reação entre atores é de } \\
\text { horizontalidade e se propõe desde uma } \\
\text { paridade de participação, isto é, todos } \\
\text { os atores relevantes (especialistas, } \\
\text { políticos, docentes, pais, estudantes, } \\
\text { movimentos sociais) são considerados } \\
\text { desde o início como grupos cujos } \\
\text { interesses devem ficar representados } \\
\text { no desenho da política, além de serem } \\
\text { protagonistas nos processos de colocar } \\
\text { em ação e avaliação permanente de } \\
\text { dita política. Isso assegura que as } \\
\text { propostas desenhadas sejam } \\
\text { percebidas como próprias e tenham } \\
\text { mais sentido. }\end{array}$ \\
\hline Visão do Outro & $\begin{array}{l}\text { Existe distancia entre os atores vistos } \\
\text { como gestores de política } \\
\text { (especialistas, governo), e aqueles } \\
\text { encarregados de implementar } \\
\text { políticas na prática, o que provoca } \\
\text { uma falta de reconhecimento mútuo } \\
\text { dos saberes e experiências de cada } \\
\text { um, desde uma essência de suas } \\
\text { identidades. }\end{array}$ & $\begin{array}{l}\text { Os atores dialogam desde princípios de } \\
\text { confiança e solidariedade em condição } \\
\text { paritária de atores participantes, o que } \\
\text { gera um reconhecimento mútuo de } \\
\text { seus saberes e experiências, todos os } \\
\text { quais são considerados relevantes no } \\
\text { processo de construção e acionamento } \\
\text { da política. }\end{array}$ \\
\hline
\end{tabular}

Fonte: elaboração própria

O chamado é, então, em direção à necessidade de uma nova proposta profunda da forma em que os processos de tomada de decisões em política educacional se conceitualizam no presente. Em primeiro lugar, a evidência nacional e internacional foi contundente em destacar que a lógica atualmente predominante está longe de ser efetiva em termos de conseguir um acionamento das políticas que redunde em um melhoramento da experiência educativa dos 
atores das comunidades escolares e, em termos de que as intenções da política se cumpram na prática. Em segundo lugar, o enfoque atual se confronta com uma série de obstáculos associados às injustiças de participação, desde as quais emergem consequências negativas que evitam a construção de sentidos compartilhados, e, a partir dali, políticas que sejam percebidas como positivas e benéficas por todos os atores. Assim, devemos propender no futuro a um desenho de políticas que inclua, desde o início, a perspectiva de todos os grupos de interesse envolvidos, com paridade de participação e desde relações horizontais, respeitosas e genuinamente dialógicas. Todas estas visões devem ficar representadas naquilo que se desenhe, assumindo uma co-responsabilidade reflexiva ao longo de todo o processo, algo que poderíamos conectar com o princípio de justiça reflexiva de Fraser (2008), em termos de capacidade de gerar políticas reflexivas, tanto na sua elaboração como na sua implementação, abertas ao que as condições de justiça e injustiça são dinâmicas, com o fim de que o avanço na paridade participativa hoje não passe a ser um obstáculo no futuro.

AGRADECIMENTOS: Os autores querem agradecer, para o caso do primeiro projeto aqui apresentado, o financiamento proveniente do fundo Iniciativa Bicentenário de Revitalização das Humanidades, as Artes, as Ciências Sociais e Ciências da Comunicação, da Universidade do Chile, e, posteriormente de CONICYT, no marco do projeto FONDECYT Iniciação $\mathrm{N}^{\circ} 11170316$. Também, em relação com o projeto de Valparaíso, os autores querem agradecer o financiamento de CORMUVAL. Por outro lado, nenhum dos projetos teria sido possível sem os membros de ambas equipes, cuja participação queremos reconhecer aqui. A equipe do primeiro projeto, em suas duas fases de financiamento, contou com o trabalho de Cristian Cabalin, Jenny Assaél, Paulina Contreras, Eduardo Santa Cruz, Loreto Montero, Francisca Corbalán, Felipe Acuña, Joaquín Deutelmoser, Verónica Carreño, Jennyfer Poblete, Sandra Rivera, Alexis Echeverría, Javiera Quiroga e Camila Cárdenas. No marco do projeto de Êxito Escolar de Valparaíso, queremos reconhecer a participação de Silvana Sáez, Pamela Soto e Claudia Rojas, além dos coordenadores e coordenadoras pedagógicos/as de CORMUVAL. Por parte de AaS: Álvaro Ayala, Javier Campos, Catalina Cuenca, Beatriz Fernández, Fernanda del Pozo, Tamara Rozas, Felipe Acuña, Manuela Mendoza, Jorge Muñoz, Evelyn Palma, Patricia Guerrero, Paulina Castillo e Francisca Corbalán. Como parte da equipe da Universidade do Chile: Rebeca Soto, Pilar Guzmán, Andrea Carrasco, Pamela Valenzuela, María Olga Gallardo, Alejandra Farías, Constanza Caracci, Mariana Cornejo, Sandra Rivera, Claudio Fuentes, Paula Rebolledo, Daniela Pitrón e Javier Álvarez. Reconhecer também aos líderes pedagógicos das cinco escolas piloto: Pablo Álvarez, Ángela Concha, Rodrigo Valenzuela, BelénVillena, Francisca Lastra, Yudis Jiménez, Angiara Aedo e Carla Pagliattini, junto com as equipes de Exito Escolar e os professores destas e de outras escolas que se envolveram e acreditaram no projeto. 


\section{REFERÊNCIAS}

BOWE, R.; BALL, S.; GOLD, A. Reforming education and changing schools. Case studies in policy sociology. 1. ed. Londres: Routledge, 1992. p. 192.

BALL, S. J.; JUNEMANN, C. Networks, new governance and education. 1. ed. Bristol, UK: The Policy Press, 2012, p. 167.

BALL, S. J.; EXLEY, S. Making policy with 'good ideas': Policy networks and the 'intellectuals' of New Labour. Journal of Education Policy, ReinoUnido, v. 25, n. 2, p. 151169, 2010.

BALL, S.; MAGUIRE, M.; BRAUN, A. How schools do policy: Policy enactments in secondary schools. 1. ed. Londres: Routledge, 2012. p. 173.

BALL, S. J. The micro-politics of the school. Towards a theory of school organization. 1. ed. Londres y Nueva York: Routledge, 2012. p. 307.

BELLEI, C. EI gran experimento: Mercado y privatización de la educaciónchilena. 1. ed. Santiago de Chile: LOM, 2015. p. 254.

DE SOUSA, B. Descolonizar el saber, reinventar el poder. 1. ed. Santiago de Chile: LOM, 2013. p. 117.

ENTMAN, R. Framing bias: Media in the distribution of power. Journal of Communication, Reino Unido, v. 57, n. 1, p. 163-173, 2007.

FLÓREZ, T. Repensar laevaluación a gran escala enfunción de una formación integral: análisis crítico de los sistemas vigentes y posiblescaminos alternativos. In: ARRATIA, A.; OSANDÓN, L. (Eds.). Políticas para el desarrollo del currículum: reflexiones y propuestas. Santiago: UCE-MINEDUC y UNESCO, 2018. p. 417-456

FRASER, N. Escalas de justicia. 1. ed. Barcelona: Herder, 2008. p. 294.

KEDDIE, A. Schooling and social justice through the lenses of Nancy Fraser. Critical Studies in Education, Queensland, Australia, v. 53, n. 3, p. 263-279, 2012.

LARNER, W. C-change? Geographies of crisis. Dialogues in Human Geography, EE.UU., v. 1, n. 3, p. 319-335, 2011.

LINGARD, B.; SELLAR, S. Globalization, edu-business and network governance: the policy sociology of Stephen J. Ball and rethinking education policy analysis. London Review of Education, ReinoUnido, v. 11, n. 3, p. 265-280, 2013.

LINGARD, B.; KEDDIE, A.Redistribution, recognition and representation: working against pedagogies of indifference. Pedagogy, Culture\&Society, Queensland, Australia, v. 21, n. 3, p. 427-447, 2013. 
OLAVE, J.M. Relatos de experiencias de evaluación. ComprensionesDecoloniales de laescuela Chilena 2013-2018. 2018. Tesis (Doctoral) - Universidad de Manizales Centro Avanzado de Niñez y Juventud, 2018. p. 243.

STOBART, G. Tiempos de pruebas: Los usos y abusos de laevaluación. 2. ed. Madrid, España: Morata. 2010. p. 236.

\section{Como referenciar este artigo}

PETOUR, M. T. F.; ASTORGA, J. M. O. Em direção a uma construção participativa da política educacional: a proposta alternativa do projeto de êxito escolar em Valparaíso. Revista on line de Política e Gestão Educacional, Araraquara, v. 24, n. esp. 1, p. 867-888, ago. 2020. eISSN:1519-9029. DOI: https://doi.org/10.22633/rpge.v24iesp1.13790

Submetido em: 20/02/2020

Revisões requeridas: 30/04/2020

Aprovado em: 28/06/2020

Publicado em: 01/08/2020 